\title{
Autopista Costanera Norte: un análisis crítico desde la ética cívica
}

\author{
Ana María Álvarez Rojas*
}

\section{RESUMEN}

Este trabajo tiene como propósito reflexionar a la luz de la Ética Cívica propuesta por la filósofa Adela Cortina, en torno al conflicto generado el año 1997 entre la organización ciudadana "Coordinadora No a la Costanera Norte" y organismos del Estado chileno, a raíz de la construcción de la autopista Costanera Norte en la ciudad de Santiago. Seleccionamos este caso por dos razones fundamentales. Una, se trataría del primer conflicto donde la ciudadanía organizada se opone a una intervención urbana que combina intereses públicos y privados. Dos, se estima que su desarrollo y desenlace pusieron en evidencia el papel marginal de la participación ciudadana en la definición del ordenamiento territorial de la ciudad por sobre actores como el Estado y la empresa privada.

Palabras clave: Ética cívica - Mínimos éticos - Sociedad civil - Conflicto urbano

\section{Autopista Costaneira norte: uma análise crítico desde a ética cívica}

\section{RESUMEN}

Este trabalho tem como propósito refletir, a luz da Ética Cívica proposta pela filósofa Adela Cortina, em torno ao conflito gerado no ano 1997 entre a organização cidadã "Coordenadora Não a Costaneira Norte" e organismos do Estado chileno, a raiz da construção do autopista Costaneira Norte na cidade de Santiago. Selecionamos este caso por duas razoes fundamentais. Uma, tratar-se-ia do primeiro conflito onde a cidadania organizada se opõe a uma intervenção urbana que combina interesses públicos e privados. Dois, estima-se que seu desenvolvimento e desenlace colocaram em evidência o papel marginal da participação cidadã na definição do ordenamento territorial da cidade por sobre atores como o Estado e a empresa privada.

Palavras chave: Ética cívica - Mínimos éticos - Sociedade civil - Conflito urbano.

* Chilena. Trabajadora Social Pontificia Universidad Católica de Chile, Doctora en Arquitectura y Estudios Urbanos, Pontificia Universidad Católica de Chile. Académica e investigadora Universidad Católica Silva Henríquez. 


\section{"Costanera norte" motorway: a critical analysis from civic ethics}

\section{ABSTRACT}

This work attempts a reflection from civic ethics on philosopher Adela Cortina's proposals about the 1997 conflict between "Coordinadora No a la Costanera Norte" and Chilean State bodies due to the construction of the "Costanera Norte" motorway in Santiago. This work chose this case study for two main reasons: it is the first urban intervention event involving public as well as private interests which is opposed by organised citizens, and because the conflict development and outcome evidenced the marginal role of civic participation in the definition of territory arrangements and the privileged position of the State and private companies in this matter.

Key words: civic ethics - minimal ethics - civil society - urban conflict

\section{Contexto general de la discusión}

\section{Sociedad civil}

Según Cortina (2002) la definición más recurrente de sociedad civil, la entiende como asociaciones e instituciones de naturaleza espontánea y voluntaria no sometidas directamente al control estatal. Se trataría de un espacio de asociación humana sin coerción, a lo que se suma el conjunto de relaciones que se dan al interior de dicho espacio. Esta autora hace una interesante distinción entre la llamada Sociedad Civil Burguesa y la Sociedad Civil a secas. El núcleo de la primera sería el individuo, sus derechos, libertades e intereses, los que deben defenderse sin interferencia a través de la competencia y la cooperación. Se trata de una "esfera cuya subsistencia y autonomía deben venir garantizadas por una institución pública llamada Estado" (p.363), que debe abstenerse de someterla o coaccionarla. Este tipo de sociedad civil se asocia al desarrollo del capitalismo en Europa entre los siglos XVII y XIX. En tanto, la sociedad civil "a secas" o "sociedad cívica", aunque conservaría muchos de los valores conquistados por la burguesía, encerraría una aspiración más inclusiva y universal acorde con los desafíos de las democracias pluralistas modernas. En estos sistemas, el individuo, antes que miembro de una clase social, una nación, un partido político o el mercado, es una persona socializada al interior de una comunidad humana a la que lo ligan derechos y obligaciones (Cortina, 2002). 
Frente a los desafíos que plantea la globalización económica, la cuestión de la sociedad civil ha recobrado particular fuerza, principalmente a partir de la década del noventa, reinstalándose en el escenario social como una alternativa política a la pérdida progresiva de la capacidad del Estado de conducir proyectos de base nacional que garanticen el bienestar colectivo. Entre las principales críticas que se formulan al Estado y a la política tradicional en clave "cívica", está su tendencia a asumir la condición política del ciudadano para ponerla al servicio de los intereses del gobierno de turno.

Para Habermas (1987), la sociedad civil representa una de las dimensiones básicas de las sociedades modernas, y por lo tanto, una esfera fundamental del funcionamiento democrático contemporáneo. Ella correspondería a lo que el autor llama "el mundo de la vida", animado por la solidaridad y sostenido sobre la racionalidad y la acción comunicativa. "El concepto de acción comunicativa presupone el lenguaje como medio dentro del cual tiene lugar un tipo de proceso de entendimiento en cuyo transcurso los participantes, al relacionarse con un mundo se presentan unos a otros con pretensiones de validez que pueden ser reconocidas o puestas en cuestión" (1987:143). La racionalidad comunicativa es, en consecuencia, el tipo de razonamiento que antecede a esta acción y que reconoce en las propiedades del lenguaje, la herramienta fundamental para el establecimiento de diálogos libres de coerción. Junto con esta esfera, el autor identifica el subsistema político, orientado por el poder, y el subsistema económico, orientado por el dinero. En ambos casos la racionalidad y la acción son estratégicas. Habermas (1987) excluye de la sociedad civil el poder político y el económico para vincularla con asociaciones voluntarias, no estatales y no económicas en las que se traducen las estructuras comunicativas de la opinión pública y el mundo de la vida: familia, movimientos sociales o asociaciones cívicas que expresan opiniones e intereses a través del espacio de una esfera pública autónoma.

Reilly (1999), aplicando este análisis a Latino América, sostiene que "el nexo sociedad civil-mercado-Estado incluye tanto oportunidades como desafíos" (...) estos tres actores "representan potencialmente un sistema sano de controles y equilibrios que hasta ahora faltó en las sociedades latinoamericanas" (p. 219). Un Estado pequeño, puntualiza Reilly (1999), no obstante la privatización de algunos servicios, puede mejorar su gestión pública, los líderes del mercado pueden tomar la ciudadanía corporativa con seriedad, las sociedades pueden hacerse más 
civiles por medio de la solidaridad y la responsabilidad social. Sin embargo, la realidad muestra un gran desequilibrio entre ellos; siendo la sociedad civil el actor más débilmente configurado en la mayoría de las democracias pluralistas modernas. Uno de los principales factores que inciden en el bajo empoderamiento de la sociedad civil, es lo que Lechner (1996) describe como la mercantilización de las relaciones sociales y el moldeamiento de un nuevo tipo de sociabilidad. Esta se circunscribiría al cálculo racional instrumental, imprimiendo a las relaciones sociales un sello individualista-egoísta, que produce una retracción de la sociabilidad. Racionalidad estratégica y comunicativa se tienden a distanciar: el poder político al que se asocia la racionalidad estratégica ha perdido su legitimidad y no intenta recuperarla a través de una actitud dialógica, plural y abierta. Al contrario, se observa instrumentalización de los electores, politización de las estrategias de búsqueda de adherentes, casos de corrupción y un deterioro de las solidaridades (Cortina, 2002).

Otro aspecto que conviene subrayar, se relaciona con lo que García-Canclini (1995) llamó la confusión del ejercicio del rol de ciudadano con el de consumidor, definiendo esta última condición los rasgos de nuestra actual ciudadanía y no el despliegue o la exigibilidad de los derechos ciudadanos (políticos, sociales y civiles). Para Cortina (2002), las responsabilidades públicas son colectivas, lo que induce a pensar que todos los poderes pueden y deben legitimarse comunicativamente. En este marco, lo económico también pertenecería al mundo de la sociedad civil y la racionalidad comunicativa y estratégica, debieran jugar un papel esencial en los tres subsistemas.

En síntesis, la sociedad civil sería, siguiendo a Cortina (1998), aquel espacio constituido por las organizaciones e instituciones del mundo económico, por las asociaciones voluntarias (comunidades adscriptivas y voluntarias, asociaciones cívicas) y por la esfera de la opinión pública. En su interior convergerían la racionalidad estratégica y la comunicativa, la competencia de intereses y la cooperación, el individualismo egoísta y la solidaridad, todo ello en un contexto de voluntariedad y pluralismo. Si aplicamos este análisis a la realidad del país al momento en que se propone la construcción de la autopista Costanera Norte, Chile se caracteriza por una opinión pública débil, desinformada y observadora pasiva, que ejerce un escaso control sobre el contenido de la información que recibe a través de los medios, baja circulación de prensa pluralista e 
ideológicamente heterogénea, crisis de participación política y desperfilamiento de los partidos como instituciones privilegiadas de canalización de la opinión ciudadana y deslegitimación de las estrategias colectivas (Lechner, 1996; Hopenhayn, 1995). Todo ello habría configurado una situación de crisis del tejido social dejando abierto el paso a la imposición de la lógica del mercado en la vida colectiva.

\section{Ciudadanía}

Por su parte, la noción de ciudadanía se relaciona estrechamente con la cuestión de la calidad y forma que adquiere la convivencia social en tanto modo de entender y experimentar lo público (Menéndez-Carrión, 1991). El declive de la dimensión pública de la vida en sociedad, señala Menéndez Carrión (1991), ha traído consigo el desdibujamiento de la ciudadanía como referente básico para la constitución de identidades, en el contexto de sociedades y de procesos de socialización que trivializan la práctica ciudadana. En América Latina, la ciudadanía se entendió hasta la década de los ochenta fundamentalmente referida a la dimensión de estatus jurídico que ella suponía, se trata de una "abstracción fundante del ordenamiento político-territorial que el estado de derecho da por sentada, o como noción que evoca la representación de una sociedad simbólicamente homogénea en los derechos y deberes de sus miembros y las condiciones (jurídicas) para poder "conferirla" y ejercerla" (MenéndezCarrión, 1991:185).

La autora citada sostiene que en décadas anteriores el debate político y social se centró en contenidos vinculados a la estructura de clases, los modelos de desarrollo, los sistemas de dominación y control social y, en muy bajo grado, al tema de la ciudadanía. Para ella, la discusión en relación a la cultura política estuvo marcada por un fuerte énfasis culturalista/historicista que privilegió una explicación del subdesarrollo de América Latina como consecuencia de la subordinación a una práctica y a un discurso hegemónico en torno al patrimonio y la autoridad; excluyendo de este debate la dimensión cívica de esta relación (MenéndezCarrión, 1991). La incorporación de la dimensión cívica al debate acerca de la profundización democrática que tendría lugar a partir de la década del '90, habría supuesto una discusión previa sobre la cuestión de la gobernabilidad, lo que no ocurrió.

Barros, De los Ríos y Torche (1999) citando a Alejandro (1993), señalan que la ciudadanía adquiere dimensiones de 
universalidad y se entiende como una estructura legal que regula las relaciones entre personas que son -ante todo- individuos. Así, otorga una igualdad en términos abstractos que hace posible la universalidad a través de la ley, creando una comunidad legal con lazos que sustentan esa legalidad (ciudadanía abstracta que posibilita lo universal). Frente a esta concepción, la pregunta que surge para América Latina es si la ciudadanía constituye sólo una categoría formal ante la exclusión social de las mayorías. Esta condición no afecta solamente a aquellos que están fuera de la cultura escrita, adhieren a normas o categorías tradicionales o se encuentran en situación de pobreza, sino también a quienes acumulan desventajas sociales durante largos períodos, aun cuando hayan podido integrarse a algunos sistemas sociales (Barros, De los Ríos y Torche, 1999). Para Rawls, precisan las mismas autoras, la ciudadanía describe la categoría de miembro permanente de una "sociedad bien ordenada" y como un esfuerzo por construir consenso sobre una concepción de la justicia en tanto equidad en el contexto de una sociedad democrática. En tanto, para Marshall, la ciudadanía debiera conducir a la igualdad social y política. En esta perspectiva, esta noción posee una gran potencialidad para la inclusión de las personas, en tanto todos los individuos serían considerados iguales ante la sociedad. Bajo esta forma, la integración adquiere la calidad de derecho, y por lo tanto, es exigible y debe ser resguardada por la institucionalidad vigente en cada período (Barros, De los Ríos y Torche, 1999).

Borja (2003) propone que la ciudadanía se constituya en aquello que reemplace u ocupe el lugar que en el pasado caracterizó al Estado Benefactor en su rol de generador/articulador de identidades y de instancia de cohesión social. Ello, a condición de que los miembros de una sociedad se reconozcan referidos homogéneamente a ella en el ejercicio de sus derechos. Asimismo, la ciudadanía debiera interpelar un registro afectivo/ simbólico en el sentido que individuos y comunidades se sientan legítimamente convocados y consientan configurar su identidad sobre la base de los principios que sustentarían la condición de ciudadano. Para este autor, el Estado Benefactor, más allá de las críticas que legítimamente le puedan ser formuladas, intentó restablecer la unidad del lazo social perdido como efecto de la modernización y del capitalismo; así como también, buscó asegurar la supervivencia del colectivo, contribuyendo a perfilar un proyecto de base nacional con un fuerte acento redistributivo. La globalización reduce el margen de maniobra económica y 
política de los Estados Nacionales a la par que se fortalecen y expanden las transnacionales. Mientras la globalización crea problemas sociales, ecológicos, económicos y de identidad, que son esencialmente políticos y cuya solución es reclamada por los ciudadanos al sistema, socava las bases de dicho sistema, incapacitándolo para resolverlos (Borja y Castells, 1998).

\section{La ética cívica: la cuestión de los mínimos éticos}

El tema de los mínimos se ha constituido en los últimos años en un eje central de los debates ético/políticos acerca del desarrollo. Estos mínimos se referirían a aspiraciones y valores que, configurados como condiciones normativas, es posible universalizar, puesto que, si bien se anclan en la dimensión autónoma del sujeto, encierran ideales de justicia colectiva en el entendido que apelarían a una voluntad autónoma de dejarse orientar por lo que "todos podrían querer" (Cortina, 1998, 2002). Los mínimos, cercanos a la idea de justicia, tendrían que ver con la existencia de una sociedad justa, en cuya generación y mantenimiento el Estado jugaría un papel clave. De hecho, el Estado debe asegurar a todos los habitantes de su país condiciones básicas en los distintos aspectos y ámbitos sociales requeridos para una convivencia pacífica, acogedora y acorde con la dignidad humana (Cortina, 1998). En tanto, los máximos serían las aspiraciones de felicidad o bienestar individual vinculados a proyectos biográficos de autorrealización, siendo las religiones, según esta misma autora, las encargadas de proponer modelos de referencia o de vida que satisfagan estas aspiraciones en los individuos. La satisfacción de una ética de máximos supone la posibilidad de establecer y concretizar una ética de mínimos (Cortina, 1998, 2002).

Así, para Cortina (2002) una sociedad pluralista, sería aquella en la que los ciudadanos comparten unos mínimos para constituir una base común. Estos mínimos refieren a ciertos derechos compartidos, a la valoración de una actitud dialógica y al aprecio de valores compatibles con una democracia liberal. Estos mínimos no serían objeto de consenso fáctico, sino la condición para que cualquier acuerdo tenga sentido legítimo (2002). En cuanto a su contenido, esta ética parte de la base que la moral cívica es un hecho. En las sociedades pluralistas se han aceptado ciertos derechos, valores y actitudes que bajo la forma de unos 
mínimos compartidos, dan pie a la configuración de la ética cívica.

Cuando habla de derechos la autora está pensando en los Derechos Humanos de la primera, segunda y tercera generación propuestos por Marshall en 1948. Suele llamarse primera generación a los derechos civiles y políticos que releva el liberalismo: derecho a la vida, libertad de opinión, creencia, culto, desplazamiento, participación. La segunda generación de derechos estaría, por su parte, conformada por los derechos económicos, sociales y culturales. Son los derechos conquistados por los movimientos sociales y dan apoyo real a las libertades. Según la autora, un Estado social de derecho está obligado como exigencia de justicia a satisfacer derechos sociales, económicos y culturales de los ciudadanos y éstos, por su parte, a ser sensibles a este sentido de justicia y a la posibilidad de exigirlo. Ambas generaciones de derechos están reconocidas en la Declaración de Derechos Humanos de la ONU. Los derechos de tercera generación, aún no reconocidos por la Declaración Universal, pero presentes según Cortina en la conciencia social y en algunas legislaciones locales, refieren a la posibilidad de gozar de un medio ambiente sano no contaminado de polución y de ruido, el derecho a nacer y a vivir en una sociedad en paz, condiciones o requisitos fundamentales para alcanzar o preservar los derechos de las primeras generaciones de derechos humanos. Cortina piensa en la necesidad de introducir una cuarta generación de derechos que subraye la importancia de la privacidad y el derecho a la preservación del patrimonio genético de la humanidad (1998).

Respecto al tema de los valores como componentes de la ética cívica, Cortina sostiene que a cada generación se asocia un valor central. Es así como a la primera generación se asocia la libertad: independencia y posibilidad de participar en las leyes vigentes, legitimidad en la búsqueda de diferentes modelos de felicidad. La segunda, en tanto, se asocia al valor de la igualdad, entendida como ausencia de dominación y a la fraternidad, que luego se transformó en solidaridad con la influencia socialista; y la tercera, al valor de la solidaridad: solidaridad mundial e intergeneracional. La cuarta generación, se vincularía nuevamente con el tema de la libertad, la que, en un sentido negativo, se aplicaría a la idea de independencia del Estado y posibilidades de autodeterminación, mientras que en un sentido positivo, a la participación en las decisiones. 
El último componente de la ética cívica es la denominada actitud dialógica. El referente ético conceptual que sirve de soporte a este rasgo, es la teoría de la acción comunicativa de J. Habermas y la ética comunicativa de Karl Otto Apel y Jurgen Habermas (Cortina, 2002). La ética comunicativa parte por considerar que los seres humanos realizamos acciones comunicativas que son aquellas en las que dos personas tratan de entenderse sobre algo. Si hablante y oyente realizan actos de habla, significa también que implícitamente se están reconociendo como personas, es decir, como interlocutores válidos. El hablante, señala Cortina, obedece a cuatro pretensiones de validez del habla (inteligibilidad, veracidad, verdad y corrección). El hecho de hacer actos de habla, supone el reconocimiento mutuo como personas capaces de actos comunicativos y de defender posiciones a través del diálogo. La duda sobre la inteligibilidad y veracidad se resuelven por la experiencia mediante la constatación directa. Mientras que para la verdad o corrección, la única posibilidad es exponer los argumentos en que se apoya cada hablante para tener la proposición verdadera o la norma correcta (Cortina, 1998). Se inicia el proceso de argumentación en el que sólo tiene sentido introducirse si los interlocutores están seriamente interesados en averiguar si la proposición es verdadera o la norma correcta. ¿Cómo se distingue la actitud de quien argumenta en serio de quien no lo hace? Quien argumenta en serio, sostiene Cortina, se atiene a determinadas reglas que convierten al diálogo en discurso práctico. Estas reglas son: la de una lógica mínima y reglas éticas, más la aplicación, una vez producidas las normas que orientarán el intercambio discursivo, de dos principios: el de universalización (reformulación dialógica del imperativo kantiano de la universalidad) y el principio de la ética del discurso, según el cual "sólo pueden pretender validez las normas que encuentran (o podrían encontrar) aceptación por parte de todos los afectados, como participantes en un discurso práctico" (Habermas, en Cortina, 1995:143). El acuerdo sobre la corrección de una norma no puede ser nunca un pacto, fruto de una negociación, sino un acuerdo unánime.

\section{La autopista Costanera Norte}

Según consigna el sitio oficial de la autopista: "El proyecto Concesión Internacional Sistema Oriente-Poniente, conocido como Costanera Norte, constituye la primera concesión de una autopista urbana en la Región Metropolitana. Tiene una longitud de 41,75 kilómetros, su velocidad de diseño 
es de $100 \mathrm{~km} / \mathrm{h}$ (80 km/h en el túnel) y se estima que unos 150.000 vehículos circularán por esta moderna vía. En su recorrido involucra a 11 comunas: Lo Barnechea, Vitacura, Las Condes, Providencia, Recoleta, Santiago, Independencia, Quinta Normal, Renca, Cerro Navia y Pudahuel, con más de 1,5 millones de habitantes“" . Esta gran obra vial comenzó a operar el día 12 de abril del año 2005, durante el gobierno del Presidente Ricardo Lagos y constituyó el primer contrato de concesión de autopistas urbanas para la capital, estando conformado por los ejes viales oriente-poniente de una longitud de 35,6 kilómetros que recorre la ciudad en este sentido por la ribera norte del río Mapocho, entre el puente la Dehesa hasta la intersección con la Ruta $68^{2}$.

Al describir sus beneficios, se subraya la capacidad de esta autopista de interconectar once comunas del Gran Santiago, mejorando la conexión entre el oriente, el centro y el poniente de la ciudad y entre las riberas norte y sur del río Mapocho, lo que se hace posible gracias a la construcción de nueve puentes y el reemplazo de tres existentes. El sistema electrónico de cobro de peajes, junto con su velocidad de diseño, "disminuyen la congestión, rebajando significativamente la emisión de gases como el monóxido de carbono de compuestos orgánicos volátiles y de material particulado“3. Asimismo, ofrecería mayor seguridad y confort a los usuarios, además de incorporar 40 hás de áreas verdes. "Las obras incluyeron la construcción de nuevas defensas fluviales en el río Mapocho, el mejoramiento de las existentes, la canalización del río y el revestimiento de su lecho“4. Otra de sus ventajas, es que cuenta con una red de fibra óptica que comunica en tiempo real a su Centro de Operaciones con los puntos de pago, cámaras de video, sistemas de emergencia, ventilación, medición de la calidad del aire y extinción de incendios, incluida "cartelería variable, citófonos SOS, ambulancias, primeros auxilios, asistencia mecánica y una serie de otros servicios, durante las 24 horas en que el Centro de Operaciones monitorea el funcionamiento de la autopista"5.

No obstante los atributos y ventajas descritos, esta obra vial desató importantes controversias antes, durante y después de su instalación definitiva. Para el urbanista Pablo Allard, esta controversia es natural dado que se te trata de la primera

$1 \mathrm{http}: / /$ www.concesiones.cl/index.php?option=com_contentEtask=blogcategoryEid=88EI temid $=140$

2 http://www.skyscrapercity.com/archive/index.php/t-199934.html

$3 \mathrm{http}: / /$ www.concesiones.cl/index.php?option=com_contentEtask=blogcategory $\varepsilon \mathrm{id}=88 \mathcal{E} \mathrm{I}$ temid $=140$

4 Ibíd

5 Ibíd. 
concesión vial urbana en Santiago, ciudad que en "los últimos 20 años, con excepción de la línea 5 del Metro, no había experimentado una intervención tan radical en términos de infraestructura en su tejido urbano; más aún, considerando que esta obra cruza la ciudad en su eje más sensible y neurálgico: el estrangulado corredor oriente - poniente, atravesando de paso 11 comunas tan diversas y opuestas como Vitacura y Cerro Navia" (Allard, 2002:1).

Por su parte, para la organización Ciudad Viva, uno de los principales colectivos urbanos que se opuso tenazmente a este proyecto a través de la "Coordinadora No a la Costanera Norte", la autopista no contribuiría a resolver los graves problemas de congestión y contaminación que afectan a la ciudad de Santiago. Esta agrupación denunció, además, el carácter elitista de la obra, pues favorecería a una minoría que ya goza de innumerables beneficios. Del mismo modo, la organización la calificó como un gesto de inconsecuencia de la autoridad pública en cuanto a su voluntad de descontaminar Santiago, pues, junto con generar más contaminación, en nada contribuye al mejoramiento de la movilidad de la mayoría de los habitantes de la capital, usuarios del transporte público (Sagaris y Araya, 1997, p.7).

En un texto de denuncia que va en la línea de las críticas formuladas por Ciudad Viva, presentado como recurso de protección a la Corte Suprema por un grupo de Ingenieros y Arquitectos urbanistas, se indica que las autopistas de alta velocidad de "gran auge hace cincuenta años, hoy se baten en retirada, y están siendo reemplazadas en el mundo desarrollado por los enlaces tren/ avión"6. Asimismo, continúa el escrito, destacados especialistas nacionales y extranjeros, expresaron una opinión contraria al proyecto Costanera Norte, asumiendo lo que consideraron sus falencias técnicas y urbanísticas. A pesar de que hoy se encuentra construido, sigue siendo para estos profesionales, un proyecto controvertido, "sancionado a ultranza y a espaldas de la ciudadanía, lo cual constituye un lunar en nuestra democracia, y una negación de los derechos de participación de los chilenos" ${ }^{\text {" }}$. El texto destaca, además, el alto costo de inversión que significó la autopista: US\$ 500 millones, “subsidiada por el Estado indebidamente en un 31\%, con recursos económicos de todos los chilenos, fue diseñada para una elite que no representa a más del tres o cuatro por ciento de la población de seis millones de habitantes de Santiago“8, elite 
que a juicio de los autores del escrito, mide la calidad de vida de la ciudad por "los minutos que se ahorran en manejar desde su casa al trabajo, ojalá por una vía que les impida ver la fealdad, pobreza y segregación que campea a su alrededor. Para el resto de sus habitantes, la calidad de vida pasó de largo" $"$.

Coincidente con esta opinión, Allard llama la atención en el hecho de que "cualquier intervención en áreas consolidadas de la ciudad, como las que atraviesa la costanera norte, va a tener inevitablemente un impacto altísimo e inmediato en la estructura y funcionamiento de ésta. Los efectos más visibles e inmediatos tienen que ver con la destrucción de barrios y áreas verdes, creación de barreras artificiales y el sinnúmero de problemas y externalidades negativas que todos asociamos a una autopista de accesos controlados, en términos de ruido, congestión, incentivo al uso del automóvil, segregación y paisaje urbano. El conflicto entre los impactos locales y las necesidades específicas del proyecto de ingeniería vial aparece como uno de los elementos más críticos de la implementación del proyecto. Los problemas de impacto en Pedro de Valdivia Norte y Bellavista son una clara demostración de esto" (2002:2).

\section{Cronología del conflicto}

En el contexto de este artículo, nos centraremos en el conflicto previo a la construcción de la autopista, en tanto es en esa fase que se hace posible pesquisar la cuestión de los mínimos como marco que debiera caracterizar el proceso de toma de decisiones que afectan a un colectivo. Cabe señalar que el proyecto Costanera Norte sufrió importantes modificaciones en su trazado original, algunas de ellas atribuibles a la presión ciudadana. Desde su licitación, en el año 1997, hasta que empieza a operar en abril de 2005, se suscitaron una serie de controversias que vuelven imposible la descripción y comprensión lineal del proceso. Por esta razón, nos centraremos en aspectos del conflicto que nos permiten una reflexión desde la Ética Cívica, sabiendo que el tema no se agota en este análisis. Tal como indica Allard, "Hablar en forma objetiva de la autopista Costanera Norte de Santiago no es nada fácil, todos hemos sido testigos de las arduas polémicas que su implementación ha desatado, el sinnúmero de emotivas notas de redacción, cartas, declaraciones públicas y lapidarios obituarios por la eventual destrucción del río Mapocho y sus barrios adyacentes. Mientras esto ocurre, la gran mayoría de los ciudadanos queda pasmada ante la envergadura y avance de las obras cada vez que cruzan el Mapocho y se detienen a ver esta intervención a 'tajo abierto'

9 http://www.defendamoslaciudad.cl/subidos/documentos/costanera\%20norte.pdf 
de la que mucho se habla y poco se sabe. La verdad es que la discusión en torno al proyecto Costanera Norte ha sido tan esquizofrénica y desinformada como su tormentoso proceso de licitación, y ya es hora que la revisemos con objetividad y cuidado, más allá de las epidérmicas preocupaciones de algunos que se atribuyen el título de defensores de la ciudad, tecnócratas con miopía sectorial, ministros presidenciables o románticos transeúntes" (2002:1).

En un principio, nos indica Correa (2001) el proyecto se plantea como una contribución a la descontaminación de la ciudad de Santiago, imprimiendo mayor fluidez al tránsito vehicular. No obstante, un conjunto de organizaciones sociales y barriales se opondrán férreamente a la construcción de la autopista, arguyendo que esa obra vial afectaría barrios consolidados y zonas del Parque Metropolitano. Estas agrupaciones cuestionan el proyecto de ciudad que está implícito en la idea de construir la autopista, y además, ponen en duda su contribución al bien común (p.145).

Según describen los integrantes de la entonces Coordinadora "No a la Costanera Norte"10 y actual Ciudad Viva, a fines de 1995, en una reunión de vecinos del barrio Bellavista, se planteó el rumor que la autoridad pública pensaba construir una autopista de alta velocidad, que pasaría por el sector (Sagaris y Araya, 1997, p.9). No existiendo información disponible, la organización se moviliza y consigue los planos que presenta en una asamblea realizada en marzo de 1996, a la que asisten más de 300 personas entre vecinos y representantes de organizaciones vecinales del Barrio Bellavista. A esta reunión asisten también representantes del Ministerio de Obras Públicas y los responsables del diseño de la obra, quienes se refieren al proyecto en términos vagos y generales, sin muchas posibilidades de participación de los asistentes. Sin embargo, es el punto de partida de la organización ciudadana en torno al proyecto (Sagaris y Araya, 1997).

En junio de 1996, en una asamblea en la Plaza Camilo Mori, y con una amplia cobertura de medios de prensa, se comunica públicamente la decisión de oponerse a la construcción de la autopista. En abril de ese mismo año se abre el proceso de licitación, y gracias a un recurso de protección interpuesto por las Juntas de Vecinos \# 12 y \# 13 y el Comité de Defensa del Cerro, se

10 Esta Coordinadora llegó a agrupar a 24 organizaciones con más de 50.000 personas, entre ellas, las asociaciones gremiales Tirso de Molina y La Vega Chica, Comité de Desarrollo de Bellavista, la Asociación de Comerciantes de la Periferia de la Vega y las Asociaciones de Propietarios y Arrendatarios de Independencia. 
detiene el proceso y se obliga a la autoridad pública a someter el proyecto a una evaluación de impacto ambiental (Sagaris y Araya, 1997).

La organización se inscribe como Coordinadora ante COREMA en el marco de preparación de la respuesta al informe de Evaluación de Impacto; respuesta que es presentada en un acto público mediante una conferencia de prensa. Sin embargo, el proponente evita afrontar de manera clara y directa los cuestionamientos que formula la organización. Todos los grupos que estudiaron el proyecto, salvo los proponentes y sus empleados, elaboran informes negativos al impacto ambiental de la autopista concesionada. La Coordinadora acusa limitaciones al Sistema de Evaluación de Impacto Ambiental en cuanto a la participación, planteando que no existe igualdad de información para los distintos actores, tampoco igualdad de recursos y acceso al proceso de toma de decisiones (Correa, 2001:145)

Sin embargo, y en un hecho inédito, los concesionarios aceptan modificar el trazado de la autopista, y se disponen a dialogar con los vecinos para buscar un trazado alternativo que no alterara significativamente el entorno de los principales barrios comprometidos. Esta decisión que es aceptada por el Ministerio de Obras Públicas (MOP) y recibida con beneplácito por los vecinos de Pedro de Valdivia Norte, Bellavista, Independencia y Recoleta, evita la ocupación de un "sector del Parque Metropolitano en la zona de Pedro de Valdivia Norte" (Correa, 2001).

Como principales irregularidades del proceso, podemos concluir que se llamó a licitación en forma precipitada, que no se respetaron los procedimientos para asegurar que un proyecto de esta envergadura se realizara en condiciones de información y participación ciudadanas, acorde a sus repercusiones sobre la vida urbana. Asimismo, el proyecto no parte con una evaluación inicial, porque de ser así se habría concluido que uno de los principales problemas de la ciudad de Santiago es "cómo transportar a las personas y no cómo mover más rápido los autos" (Sagaris y Araya, 1997:21). Respecto de este punto, Allard señala que "los mayores usuarios de Costanera Norte son precisamente aquellos que encarnan esta visión de la ciudad en extensión: ejecutivos que viven en La Dehesa y trabajan en el centro, amas de casa que deambulan entre el colegio de sus niños, el mall y el hipermercado; el contratista que se dirige en su furgón desde Cerro Navia al barrio alto a prestar sus servicios, y el distribuidor que lleva artículos del depósito en Carrascal a la tienda en Providencia. Para todos ellos la autopista 
se presenta como una solución muy esperada y conveniente, eso sí, a costa de aquellos que abogan por una ciudad más compacta, caminable e integrada, que viven en Providencia, Santiago Centro, Bellavista o Independencia, y que lamentablemente verán pasar los autos bajo sus narices" (Allard, 2002:2).

Finalmente, cabe señalar que en el transcurso del conflicto, la Coordinadora denuncia que el MOP se negó sistemáticamente a entregar información básica que permitiera evaluar el proyecto, "poniendo en evidencia a través del Estudio de Impacto Ambiental (EIA) en mayo de 1997, la pobreza y ausencia de estudios serios en relación a este proyecto" (Sagaris y Araya, 1997:29). El informe se entregó un mes después de llamar a la licitación y "apenas un mes antes de la fecha inicial de la apertura de las primeras propuestas" (...) Ello "sugiere un apuro desmedido que milita en contra de la calidad de un proyecto de esta enorme envergadura" (Sagaris y Araya, 1997:30).

El informe citado concluye que esta repartición nunca entregó información fundamental para estimar las ventajas y desventajas del proyecto entre las que se mencionan: el estudio de costo/ beneficio social, estudio sobre emisiones y concentraciones de gases tóxicos a lo largo del trazado como línea de base para la proyección de la obra, estudio de alternativas para resolver los problemas de congestión, contaminación y transporte de todos los usuarios, no sólo los automovilistas de esa vía (Sagaris y Araya, 1997).

\section{Análisis del caso}

Como veremos a continuación, el conflicto descrito constituye un buen ejemplo para poner en tensión los contenidos de la Ética Cívica a partir del análisis de su gestión y de la manera en que fue manejada la información y tomadas las decisiones, particularmente desde la Autoridad Pública en la "persona" del MOP.

Recordemos que un Máximo Ético, es lo que Cortina describe como las aspiraciones de felicidad o bienestar individual que cristalizan proyectos biográficos de autorrealización, encarnados en sistemas de creencias como las religiones, las ideologías políticas, entre otros. Sin embargo, en las sociedades pluralistas, la Ética Colectiva o Cívica, la del ciudadano, no puede ser reflejo exclusivo de estos ideales personales o máximos, sino que debe anclarse en aquello que es común a todos estos referentes y que llamamos mínimos. Estos mínimos han de ser objeto de un trabajo 
dialógico, que consiste en configurar estas aspiraciones y valores como condiciones normativas que es posible universalizar, en tanto, como puntualiza Cortina, si bien se anclan en la dimensión autónoma del sujeto, encierran ideales de justicia colectiva, en el entendido que apelarían a una voluntad autónoma de dejarse orientar por lo que "todos podrían querer".

Es interesante observar, respecto del caso en estudio, dos cuestiones fundamentales que llaman nuestra atención. Una, se relaciona con el hecho que desde la Ética Cívica, la Costanera Norte obedece, más bien, a la imposición de un máximo relacionado con un ideal de ciudad, y en ningún caso representa el resultado de un acuerdo unánime entre actores, tal como este enfoque lo sugiere. Otra, se vincula con el deficiente papel jugado por el Estado, en vistas a crear condiciones óptimas para la generación de acuerdos cooperativos entre ciudadanos.

Recordemos que según Cortina, los mínimos cercanos a la idea de justicia, tendrían que ver con la existencia de una sociedad justa, en cuya generación y mantenimiento el Estado jugaría un papel clave. El Estado, en el caso analizado, al ser juez y parte actuando como convocante, y simultáneamente, como responsable de evaluar el impacto ambiental de la obra a través de organismos que dependen de él, invalida su independencia para generar condiciones que favorezcan el acceso igualitario a la información y posibilidades de influir en la toma de decisiones de todas las posturas en disputa.

Tal como denuncia la "Coordinadora No a la Costanera Norte“, más allá de la obra puntual, "Costanera Norte" representa o encierra un proyecto de ciudad, un ideal urbano, es decir un máximo, que entiende la ciudad esencialmente al servicio de la movilidad automovilística, descongestión, velocidad y disminución del tiempo de viaje. Eso significa, tal como lo vimos en la descripción del caso, la exacerbación de ciertas funciones a las que la ciudad debe servir, con el consiguiente beneficio que esa opción supone para aquellos habitantes que harán un uso intensivo y sistemático de la autopista, por sobre otros habitantes que encarnan proyectos de ciudad distintos a éste y que abogaron, en su momento, por dar solución el problema de la congestión vehicular sugiriendo alternativas a esta propuesta, que, desde sus máximos éticos, implicaran beneficios más colectivos.

Asimismo, los hechos que rodearon el desarrollo de este proyecto desde sus inicios, nos permite sostener que la obra encarna un 
ideal urbano asociado a la modernización en el sentido más instrumental que reviste este término, además de elitista en tanto favorece las necesidades y demandas de una minoría. Al encuentro de la perspectiva de ciudad recién referida, se opuso la de aquellos que argumentaron que en Santiago sólo un 20\% de los viajes diarios se hacen en automóvil, más del 50\% se hace en transporte público, el $5 \%$ más rico de la ciudad viaja dos veces más y utiliza un auto 40 veces más que el $20 \%$ más pobre. Los más pobres gastan $70 \%$ más de tiempo en viajes que los más ricos (Sagaris y Araya, 1997:22). Se trata de una postura a favor de una visión de ciudad más democrática y más asentada en el bien común, que aquella por la cual finalmente se optó. A ello se suma la relación entre el costo de la inversión y el beneficio público que dicha inversión trajo consigo.

Para quienes defienden la idea de ciudad como bien público, entre los cuales está Ciudad Viva, este punto acrecienta la sospecha, o más bien la evidencia, de cuál es el máximo que se está privilegiando mediante esta intervención urbana, como ya se indicó: "subsidiada por el Estado indebidamente en un 31\%, con recursos económicos de todos los chilenos, fue diseñada para una elite que no representa a más del tres o cuatro por ciento de la población de seis millones de habitantes de Santiago" ${ }^{\prime 1}$. Entonces, esta base común en la que debieran cristalizarse estos mínimos éticos, no se generó en el caso del proyecto Costanera Norte, puesto que la obra fue el resultado de un consenso fáctico, o más bien, una política de "hechos consumados" y no la definición de mínimos compartidos.

Así, una primera conclusión que surge antes de entrar en el análisis de los componentes de la Ética Cívica aplicados al caso, a saber, derechos, valores y actitud dialógica, es que esta intervención urbana no fue el resultado de un acuerdo cívico, sino la imposición de una perspectiva de ciudad coherente con las exigencias de la hipermovilidad característica de la exacerbación del espacio de los flujos, propios de la ciudad "globalizada" y una opción tácita por la ciudad en extensión o difusa (Rueda, 1998). No hubo deliberación democrática en torno a su ejecución, traducida en que estos distintos actores pudiesen poner en común sus ideales de ciudad, intentando la definición de un referente ético que sirviera de base a la discusión respecto de la autopista.

11 http://www.defendamoslaciudad.cl/subidos/documentos/costanera\%20norte.pdf 
En tal sentido, el desafío para que la Sociedad Civil se constituya como tal frente a este y otros conflictos urbanos, es que se "tome en serio" su papel de protagonista en un debate que la implica directamente, pues refiere a sus condiciones y calidad de vida como habitante. Aprovechar estas instancias para exigir la generación de un diálogo abierto e informado, por ejemplo, sobre el o los tipos de ciudad a los cuales aspira y el grado en el que estos tipos de ciudad son compatibles o excluyentes entre sí. ¿Cuáles son los fundamentos ético-políticos que subyacen a uno u otro tipo de ciudad? ¿Cuáles son las consecuencias, en distintos planos: ecológicas, medioambientales, sociales, de privilegiar determinados proyectos para resolver los problemas que nos afectan como ciudad? Sentirse parte del diálogo que supone responder a estas interrogantes, constituye un primer paso en la configuración de un ciudadano que se sienta con capacidad de ejercer derechos y exigir su respeto.

En cuanto a los derechos y valores, componentes básicos de la Ética Cívica, nos parece que esta obra pone en tensión derechos de primera, segunda y tercera generación y los respectivos valores asociados a ésta. Como derechos de primera generación, se exacerba la libertad en favor de quienes harán uso de la autopista, libertad de desplazamiento, circulación y libertad económica, al incentivar el uso intensivo de un bien privado como el automóvil, responsable de la contaminación ambiental, y por lo tanto, de la salud pública del conjunto de la población, como lo argumentó sostenidamente la "Coordinadora No a la Costanera Norte". De este modo, constatamos que "Santiago, que posee la más alta concentración del parque vehicular del país, es con toda seguridad quien aporta la proporción más alta en las emisiones de CO2 provenientes del área de transporte (Sagaris y Araya, 1997:64) (...) "Santiago ha sido declarada ciudad saturada por las contaminantes $\mathrm{CO}, \mathrm{PM} 10$ y $\mathrm{O}_{3}$ siendo el flujo del parque automotriz que circula por las vías cercanas a las estaciones de monitoreo, la principal actividad que influye en los niveles monitoreados" (1997:93).

Si miramos esta constatación bajo el prisma de las generaciones de derechos y sus valores asociados, aparentemente se tensionan libertad individual, como derecho y valor guía de la primera generación, con Justicia y Solidaridad como derecho y valor guía de la segunda generación de derechos, junto con el derecho a un ambiente libre de contaminación de la tercera generación, siendo los valores guías, en este caso, el respeto y la solidaridad inter generacional. En este punto cabe consignar dos cosas: una, que la 
generación de derechos que estaría imponiendo su racionalidad a las otras, a saber, el derecho y el valor de la libertad se vincula más estrechamente a lo que Adela Cortina identifica con la Sociedad Civil Burguesa, cuyo núcleo sería el individuo, sus derechos, libertades e intereses, los que deben defenderse sin interferencia a través de la competencia y la cooperación. Otra, es que la hegemonía del valor de la libertad individual, resulta coincidente con el modelo de sociedad actualmente vigente y, por lo tanto, encuentra correspondencia con las normas culturales que sostienen dicho sistema, imprimiendo legitimidad a las opciones individuales, muchas veces, en desmedro del beneficio colectivo.

Respecto a la idea de Sociedad Civil Burguesa, se trata de un tipo de sociedad en la cual los intereses colectivos o ciudadanos son identificados, o más bien, homologados a los intereses de una clase social, la burguesía. Por lo tanto, la tarea del Estado es generar condiciones óptimas para el despliegue de la libertad y la satisfacción de demandas específicas a este segmento. En las democracias pluralistas modernas, esta forma de entender la sociedad civil debiese haber "quedado atrás", así como también el representarse los Derechos Humanos sin vinculación los unos de los otros. Tanto los derechos como los valores asociados a una u otra generación, han de interpretarse desde una perspectiva relacional que suponga asumir la importancia de su satisfacción simultánea y sinérgica, dejando fuera jerarquías y exclusiones.

Abordar este conflicto privilegiando los intereses de un sector de la población, significa volver a nociones de sociedad civil que no se condicen con la democracia moderna, así como tampoco, la de asumir los derechos y valores desde una óptica jerárquica, que nada tiene que ver con el espíritu de la época en cuanto a entender el "desarrollo" desde una consideración simultánea de todos las dimensiones y procesos implicados en el mismo (políticos, económicos, culturales, sociales, ecológicos, medioambientales). Asimismo, la libertad no tiene apellido ni está asociada a un sector particular de la población. De ahí la salvedad de que, "aparentemente", se estaría imponiendo la libertad individual por sobre la justicia y la solidaridad. En la práctica, lo que se impone no es la libertad del ciudadano en una perspectiva de universalidad de derechos, fundamento de la ética cívica, sino la libertad de un sector minoritario. Eso hace que no estemos hablando de derechos, sino más bien de prerrogativas asociadas a ventajas sociales y económicas. Porque, en este caso, 
la hegemonía de la libertad de unos, significa un perjuicio para la libertad de la mayoría para tener, por ejemplo, oportunidades de "vivir más", de "no enfermarse", de tener una mejor calidad de vida urbana, de contar con un sistema de transporte que se transforme en primera prioridad para la inversión pública, junto con otras medidas que se hace indispensable tomar para contrarrestar y detener la contaminación. No hay libertad universal sin justicia; si no hay justicia ni solidaridad, no hay libertad ciudadana sino privilegios.

Respecto al último componente de la Ética Cívica, a saber, la actitud dialógica, sostenemos que éste resulta débil a juzgar por la forma en que se gestionó el conflicto, partiendo por lo que constituye su fundamento básico: la consideración de las partes como interlocutores válidos y la disposición a conocer, entender y legitimar las posturas en disputa. Recordemos sobre este aspecto que los hablantes obedecen a cuatro pretensiones de validez del habla (inteligibilidad, veracidad, verdad y corrección). El hecho de hacer actos de habla, supone el reconocimiento mutuo como personas capaces de actos comunicativos y de defender posiciones a través del diálogo. Si, como sostuvo la "Coordinadora No a la Costanera Norte", el rumor fue el medio a través del cual la ciudadanía se enteró de este proyecto, el que antes de las sucesivas modificaciones del trazado de las que fue objeto, implicaba una expropiación de sus viviendas, la destrucción de sus barrios y la pérdida de áreas verdes, no podemos decir que el punto de partida de esta situación, sea la validación mutua de los hablantes entre sí, fundamentalmente a juzgar por la actitud del MOP y su desconsideración hacia la opinión de los ciudadanos.

Como señalamos, la duda sobre la inteligibilidad y la veracidad se resuelven por la experiencia mediante la constatación directa, mientras que para la verdad o corrección, la única posibilidad es exponer los argumentos en que se apoya cada hablante para sostener la que cree la proposición verdadera o la norma correcta. ¿Pero cómo es posible el ejercicio de esta práctica si la información no está disponible, es confusa, contradictoria o equívoca, como lo denunciara la Coordinadora al momento de evaluar los encuentros con la autoridad pública? Recordemos que el proceso de argumentación sólo tiene sentido en el marco de esta ética si los interlocutores están seriamente interesados en averiguar si la proposición que cada una de las partes defiende, es verdadera. ¿Cómo se puede enfrentar un diálogo en estas 
condiciones cuando una de las partes asume, desde el principio, que la decisión ya está tomada?

Finalmente, cabe señalar que en el planteamiento de Habermas, en quien se inspira Cortina para fundamentar la Ética Cívica, las normas ideales y universalmente válidas serían de corresponsabilidad de quienes toman parte en el discurso, la igualdad de derechos y la susceptibilidad de consenso de todas las soluciones a los problemas que presenta la existencia social (Morales, 2003). Es por ello, que se torna fundamental generar un diálogo entre quienes serán afectados positiva o negativamente por las normas producidas y pactadas, lo que no ocurre en la situación analizada, donde los ciudadanos y organizaciones implicadas en el conflicto, se sienten meros receptores de las decisiones de otros.

Por eso se torna importante examinar dos aspectos. Uno, el grado en el cual la institucionalidad que establece los límites normativos a cada situación -en este caso, la entonces Comisión Nacional del Medio Ambiente (CONAMA) y la Comisión Regional del Medio Ambiente (COREMA) bajo la tutela del Estadoposibilitó o no la generación del diálogo y los acuerdos referidos. Dos, si lo sostenido por los distintos actores involucrados, deja en evidencia distancias o proximidades entre el núcleo normativo al cual adhieren colectivamente, al menos en el discurso y las prácticas sociales concretas asociadas a su acción; lo que daría cuenta de mayores o menores niveles de correspondencia con las normas declaradas.

Finalmente, Morales (2003) nos advierte que la ética del discurso debe distinguir también los condicionamientos socioestructurales para su propia aplicación. Es decir, sólo puede valer como justa aquella sociedad que en su infraestructura normativa dispone de presupuestos para diálogos libres de dominio que garanticen a todos sus miembros la oportunidad de una participación igualitaria y sin coerción. Es esta la condición de posibilidad para el reconocimiento colectivo de mínimos que favorezcan la constitución de una ética cívica, esencial al funcionamiento de una auténtica democracia.

¿Existe en nuestro país esta infraestructura normativa? Si no es así, ¿de qué manera favoreceríamos condiciones sociales y políticas para su surgimiento? 


\section{Bibliografía}

Allard, P. (2002). Si el Río suena, ya no es piedras lo que trae. Revista ARQ, 52, 44-49. Disponible en http://www.scielo. cl/scielo.php?script=sci_arttextEpid=S0717$69962002005200018 \mathcal{E} \operatorname{lng}=$ enEnrm=isoEtlng= en

Barros, P.; De los Ríos, D. y Torche, F. (1999). "Exclusión Social y Políticas Públicas". OIT (Organización Internacional del Trabajo).

Borja, J. (2003). La ciudad conquistada. Madrid: Alianza Editorial.

Borja, J.; Castells, M. (1998). Local y global. La gestión de las ciudades en la era de la información. Madrid: Taurus.

Correa, P. (2001). Participación ciudadana en los conflictos ambientales en los proyectos viales. Un estudio de casos: Costanera Norte, By Pass Temuco y acceso Nor Oriente (Tesis doctoral). Universidad Católica de Chile, Santiago, Chile.

Cortina, A. (1995). La Educación del Hombre y del Ciudadano. Revista Iberoamericana de Educación, 7,41-64. Disponible en http://dialnet.unirioja.es/servlet/ articulo?codigo $=1019483$

Cortina, A. (1998). Sociedad civil, en Diez palabras claves en Filosofía Política. Madrid: Verbo Divino.

Cortina, A. (2002). La Ética de la Sociedad Civil, Madrid: Editorial Alauda ANAYA.

García-Canclini, N. (1995). Consumidores y Ciudadanos. Conflictos multiculturales de la globalización. México: Grijalbo.

Habermas, J. (1987). Teoría de la acción comunicativa (Tomo I). Madrid: Taurus.

Hopenhayn, M. (1995). "Ni apocalípticos ni integrados. Las aventuras de la Modernidad en América Latina". Santiago: Fondo Cultura Económica.

Lechner, N. (1996) “¿Por qué la Política ya no es lo que fue?”. Leviatán: Revista de hechos e ideas, 63, 63-74.

Menéndez, R. (1991). El lugar de la ciudadanía en los entornos de hoy. Una mirada desde América Latina. Revista Debate, 58, 181-222.

Morales, P. (2003). La ética del discurso. Revista Perspectivas. Notas Sobre Intervención y Acción Social, 14, 3746. Disponible en http://www.ucsh.cl/Uas/ opensite_20080425121026.asp

Reilly, Ch. (1999). “El equilibrio entre el Estado, el Mercado y la 
sociedad civil. Las ONG para un nuevo consenso de desarrollo". En Tokman, V. y O' Donnell G. (Compiladores), Pobreza y desigualdad en América Latina. Buenos Aires: Editorial Paidós.

Rueda, S. (1998). "La ciudad compacta y diversa frente a la conurbación difusa". En Escuela Superior de Arquitectura de Madrid. Biblioteca: Ciudades para un futuro más sostenible. Madrid: Escuela Superior de Arquitectura de Madrid.

Sagaris, L. y Araya, R. (1997). Costanera Norte ¿Qué ciudad queremos? Coordinadora No a la Costanera Norte. Observatorio Latinoamericano de Conflictos Ambientales. 